Original Research Article

\title{
Analysis of adverse drug reactions in a tertiary care teaching hospital in Southern India
}

\author{
Nagaraja Prasad Sai*
}

Department of Pharmacology, Shivamogga Institute of Medical Sciences, Shimoga, Karnataka, India

Received: 11 February 2019 Accepted: 11 March 2019

\section{*Correspondence to:}

Dr. Nagaraja Prasad Sai, Email: drnagarajprasad@ gmail.com

Copyright: (C) the author(s), publisher and licensee Medip Academy. This is an openaccess article distributed under the terms of the Creative Commons Attribution NonCommercial License, which permits unrestricted noncommercial use, distribution, and reproduction in any medium, provided the original work is properly cited.

\begin{abstract}
Background: Medication use has been there since time immemorial. Also, it was well known that all medications carry risk of adverse drug events. Hence regular and periodic monitoring of medications for adverse events has assumed importance. With this background pharmacovigilance has an important role to play in monitoring of adverse events to medications. Hence the present study was undertaken to analyze the pattern of adverse events reported to a tertiary care teaching hospital in Southern India (Shivamogga Institute of Medical Sciences (SIMS), Shimoga).

Methods: This study is a retrospective observational study of 150 adverse drug events reported at McGann teaching hospital, SIMS, Shimoga. The adverse events reported were analyzed for their age and gender distribution, drugs causing ADRs, organ systems affected, causality, type, severity and preventability of ADRs.

Results: Patients in age groups of 21-40 were most commonly affected by ADRs with a slight increase in male population affected. Cutaneous ADRs were most common and beta lactam antibiotics were most common drug group implicated in causing these ADRs. Probable/likely category most common WHO-UMC causality category, with type A ADRs being most common. Majority of ADRs were of moderate severity and nearly $86 \%$ of ADRs were of not preventable category.

Conclusions: Antimicrobials were most commonly involved in causation of ADRs with cutaneous ADRs being most common. Most of ADR were not preventable category, majority of ADRs were of moderate severity and causality grading was probable/likely category.
\end{abstract}

Keywords: Adverse drug reactions, Adverse drug reaction monitoring centre, Causality, Pharmacovigilance

\section{INTRODUCTION}

Drug use to treat human illness dates back to prehistoric times when humans used plants and other national source to treat their illness. ${ }^{1}$ Even in those early days humans knew about the occurrence of undesired effects associated with use of drugs. Thus, monitoring of adverse drug effects during medication use is an important aspect in treatment of illness. Adverse drug reactions (ADRs) to drugs increase the morbidity and mortality, decrease the quality of life and increase the rate and duration of hospitalization as well as pose a tremendous economic burden on the society.
The monitoring of adverse effects of drugs comes under the ambit of pharmacovigilance. The term pharmacovigilance has two parts Pharmacon (Greek) meaning 'drug' and vigilare (Latin) meaning 'to keep awake or alert. Pharmacovigilance (PvG) has been defined as the science and activities related to detection, assessment, understanding and prevention of adverse effects of drugs. ${ }^{2}$ World Health Organization (WHO) defines an adverse drug reaction (ADR) as 'response to a drug which is noxious and unintended and which occurs in doses normally used in humans for prophylaxis, diagnosis, therapy of disease or modification of physiological function". 3-5 
The incidence of ADR varies widely among different studies with the incidence rates varying from $0.86 \%$ to $37 \%{ }^{6,7}$ In one study it has been reported that ADRs due to prescription and over the counter drugs affected $6.7 \%$ of patients with nearly $3.2 \%$ of them resulting in death of patients in USA. ${ }^{8}$ In one study by Rao et al it has been estimated that atleast one ADR occurred in $10-20 \%$ of hospitalized patients. ${ }^{9}$ Dose related adverse events accounted for $83 \%$ of ADRs in males and 93\% ADRs in females. ${ }^{10}$ It has been found that the incidence of ADRs is much more in geriatric, pediatric and female population, this is due to the various changes in pharmacokinetic and pharmacodynamics factors in these age groups. Also, some studies have found that females are more susceptible to gastrointestinal and cutaneous allergic adverse events. ${ }^{11-}$ 13

Recognizing the importance of monitoring the ADRs after the thalidomide tragedy in the 1960s the World Health Organization (WHO) set up the Uppsala Monitoring Centre in the year 1978 which is the internationally recognized Centre for monitoring adverse events throughout the world. As of January 2016, the WHO Programme for International Drug Monitoring has been joined by 123 countries around the world and an additional 28 'associate members' are awaiting full membership of the organization. ${ }^{14}$

In India formal PvG activities were established in the year 1986 with 12 regional centers located throughout the country. However, the program has undergone various revisions and in its present form it is functioning as the Pharmacovigilance Programme of India with the National Coordinating Centre (NCC) located at Ghaziabad (UP) from the year 2011. ${ }^{15}$

Author's institute has been recognized as an Adverse drug reaction Monitoring Centre (AMC) under the PvPI for monitoring of adverse events in Mcgann teaching hospital SIMS, Shimoga and is presently working to improve the safety and welfare of the patients in the hospital setup by working towards the early detection, monitoring and reporting of adverse events occurring in the patients visiting the tertiary care centre, SIMS Shimoga.

\section{METHODS}

The present study is a retrospective observational study of ADRs reported in our Institute. A total of 150 ADRs of patient's upto January 2019 which were reported by doctors and nurses to the SIMS AMC were collected and analyzed according to various criteria.

\section{Inclusion criteria}

- $\quad$ ADR reports of all age groups and both the genders visiting or admitted to the hospital.

- ADR reports of patients with history of consumption of drugs and presenting to the hospital with the adverse event report.

\section{Exclusion criteria}

ADR reports of patients with incomplete or inconsistent data.

Institutional ethical committee permission was obtained and the suspected adverse drug reaction reporting form version 1.3 (SADRRF) advocated by the PvPI was used to collect the information about the adverse event form the patient. ${ }^{16}$ The reported adverse events were thus subjected to further analysis under various criteria as follows:

- Age and gender distribution.

- Causality assessment method of WHO UMC (Uppsala Monitoring Committee) criteria. ${ }^{17,18}$

- Pattern and type of ADRs. ${ }^{19}$

- Severity of ADRs. ${ }^{20}$

- Preventability of ADRs. ${ }^{21}$

- Body systems involved.

- Causative drug groups.

\section{Statistical analysis}

Throughout the study strict confidentiality was maintained regarding the particulars of patients involved. Data analysis was done by using descriptive statistics.

\section{RESULTS}

A total of 150 ADR reports received so far at our AMC were analyzed. On analysis of the data it was found that age group of 21-30 years was most commonly affected $(n=39$, $26 \%)$ followed by $31-40$ years age group $(n=30,20 \%)$ pediatric age group(0-10years) was the next most commonly affected $(n=20,13.34 \%)$ (Figure 1). Analysis of the gender distribution showed a slight male preponderance $(n=78,52 \%)$ as compared to females $(n=72$, $48 \%$ ) (Figure 2).

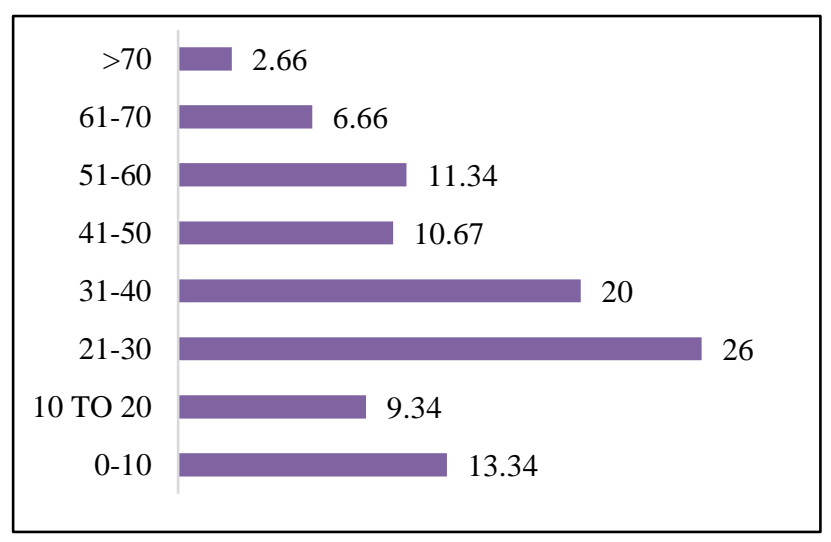

Figure 1: Age distribution of patients.

Most common causative drug groups were antibiotics $(\mathrm{n}=80,53.33 \%)$ with beta lactams being the most commonly implicated antibiotics $(n=34,22.66 \%)$. Next in line were the NSAIDs $(n=28,18.66 \%)$ followed by Central 
nervous systems drugs $(\mathrm{n}=16,10.66 \%)$ (Figure 3 and Table $1)$.

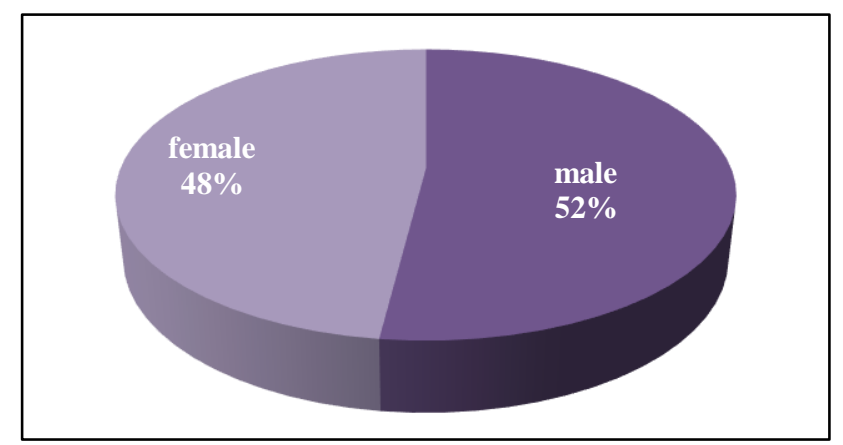

Figure 2: Gender distribution of patients.

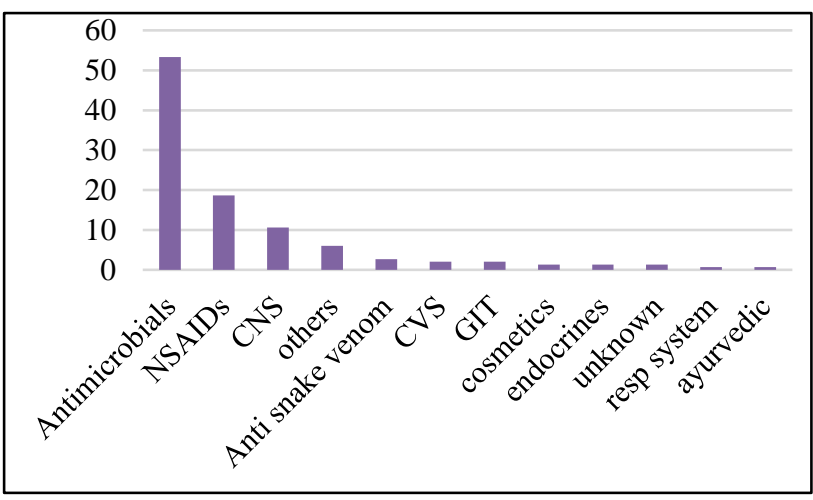

Figure 3: Drug group causing ADRs.

Table 1: Drug groups causing ADRs.

\begin{tabular}{|c|c|c|}
\hline Drug group & No. (n) & $\begin{array}{l}\text { Percentage } \\
(\%)\end{array}$ \\
\hline $\begin{array}{l}\text { Antimicrobials \{beta lactams (36), } \\
\text { anti TB (13), ART (12), } \\
\text { Quinolones (10), } \\
\text { Aminoglycosides (2), } \\
\text { Metronidazole (2), Antileprotic } \\
\text { (2), sulfa drugs (1), tetracycline } \\
\text { (1), antifungals (1)\} }\end{array}$ & 80 & 53.33 \\
\hline NSAIDs & 28 & 18.66 \\
\hline $\begin{array}{l}\text { CNS \{antiepileptic (11), } \\
\text { antipsychotics (3), general } \\
\text { anesthetic (1), tricyclic } \\
\text { antidepressants (1)\} }\end{array}$ & 16 & 10.66 \\
\hline $\begin{array}{l}\text { Other drugs }\{\text { lignocaine (4), } \\
\text { mannito } 1(1) \text {, allopurinol (1), iron } \\
\text { sucrose (1),etc. }\end{array}$ & 9 & 6 \\
\hline Antisnake venom & 4 & 2.66 \\
\hline Cardiovascular system & 3 & 2 \\
\hline GIT & 3 & 2 \\
\hline Cosmetics & 2 & 1.34 \\
\hline Endocrines & 2 & 1.34 \\
\hline Others & 2 & 1.34 \\
\hline Respiratory system & 1 & 0.66 \\
\hline Ayurveda drugs & 1 & 0.66 \\
\hline
\end{tabular}

Analysis of the adverse event symptoms revealed cutaneous ADRs $(n=61,40.67 \%)$ were most common manifestation of adverse event followed by cutaneous ADR $(n=56,37.34 \%)$, gastrointestinal symptoms $(n=10$, $6.67 \%$ ) (Figure 4).

\begin{tabular}{|r|l|}
\hline other & 6.67 \\
\cline { 2 - 2 } hepatic dysfunction & 0.66 \\
resp system & 0.66 \\
CNS & 0.66 \\
CVS & 6.67 \\
G.I.Symp & 6.67 \\
Generalised ADRs & \\
Cutaneous ADRs & \\
\hline
\end{tabular}

Figure 4: Organ systems involved in ADRs.

Causality assessment according to the WHO UMC causality assessment criteria revealed that none of the reported ADRs came under the definite category while $57.34 \%(n=86)$ came under the probable/likely category and $25.34 \%(\mathrm{n}=38)$ came under the possible category, 6\% $(\mathrm{n}=9)$ unlikely category and $11.34 \% \quad(\mathrm{n}=17)$ under unassessable category (Figure 5).

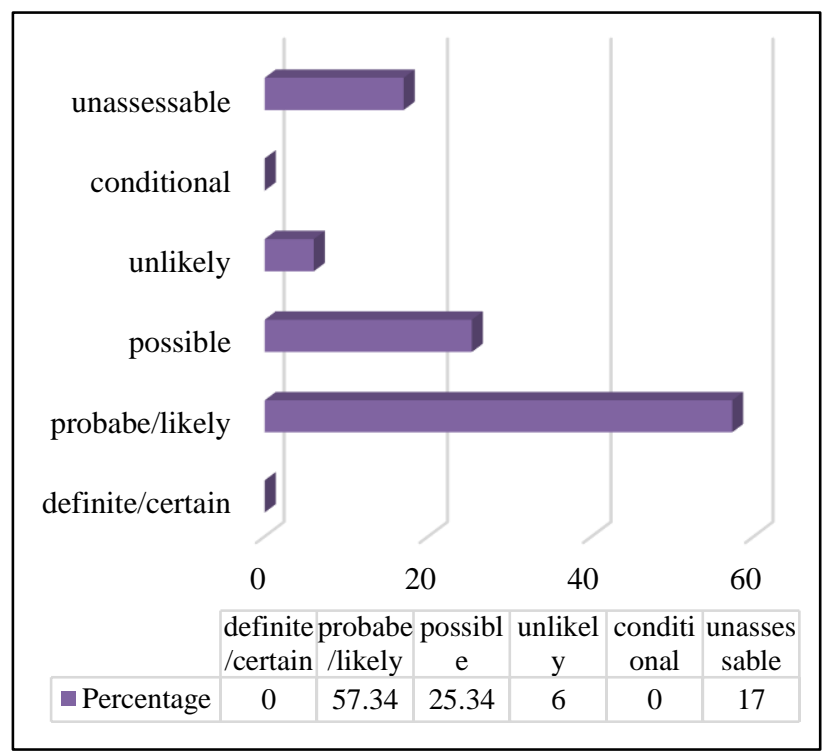

Figure 5: Causality assessment of ADRs under WHOUMC causality assessment system.

Type A ADRs accounted for nearly $84 \%(n=126)$ and type B ADRs accounted for $16 \%(n=24)$ of the total ADR according to the Rawlins and Thompson Classification (Figure 6). 


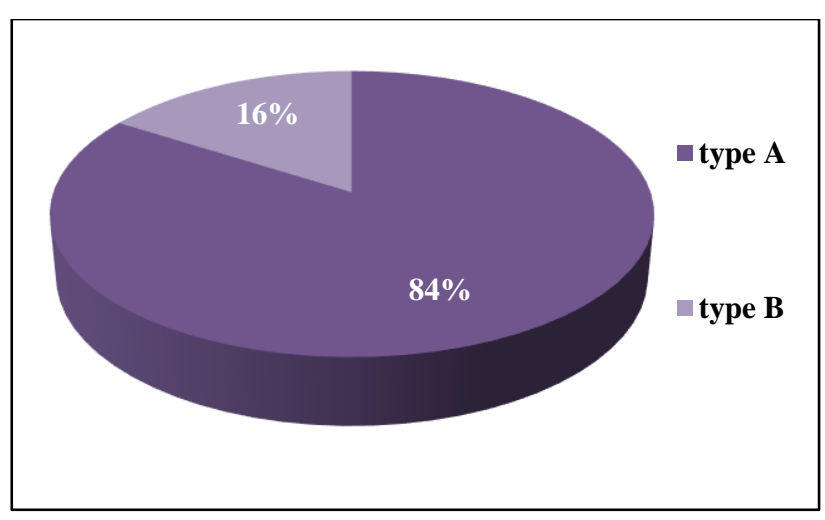

Figure 6: Type of ADRs.

Severity assessment as per Hartwig and Siegel scale revealed majority (76\%) of ADR were of moderate severity $(\mathrm{n}=114)$ and milder reactions constituted for $18 \%(\mathrm{n}=27)$ and severe reactions accounted for $6 \%(\mathrm{n}=9)$ of the total reported ADRs (Figure 7).

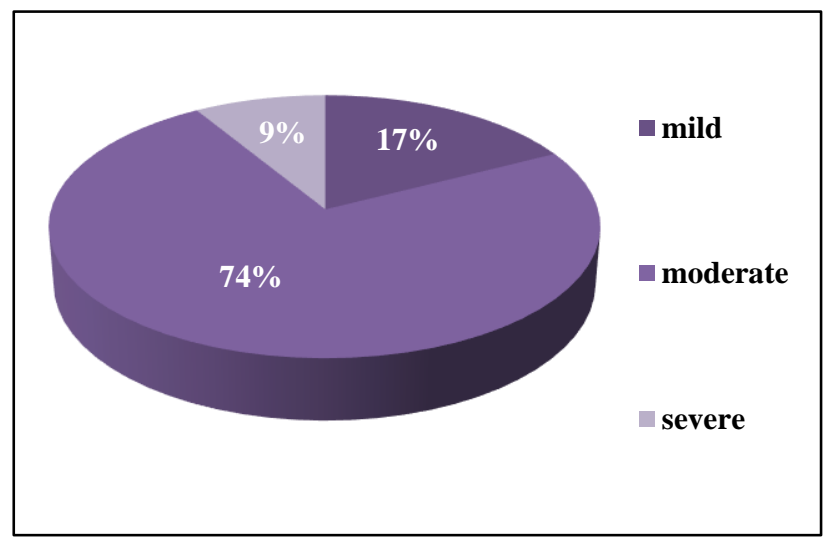

Figure 7: Severity of ADRs.

Following the Modified Schumock and Thornton criteria for preventability assessment it was found that none of the reported ADRs were definitely preventable while $86 \%$ $(n=129)$ were not preventable and $14 \%(n=21)$ were probably preventable (Figure 8).

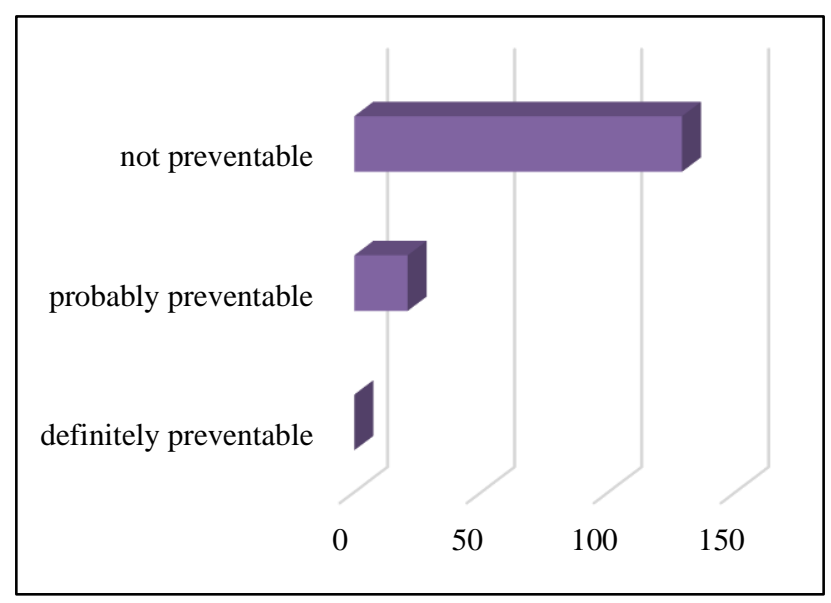

Figure 8: Preventability of ADRs.

\section{DISCUSSION}

ADR reports received so far (upto January 2019) were collected from doctors were subjected to analysis according to various criteria like age and gender distribution of the reported ADRs, drug groups causing these ADRs, symptoms of these ADRs (systems affected), type of ADRs (type A and B), severity of ADRs (mild, moderate and severe), preventability assessment (definitely preventable, probably preventable and not preventable) and according to the WHO UMC causality assessment criteria (definite/certain, probable/likely, possible, unlikely, conditional, unassessable).

Majority of the ADRs (46\%) in present study were from age group of 21-40 years these findings do not correlate well with the knowledge that ADRs are more likely to occur in the pediatric, geriatric and pregnant population groups this may be due to the fact that more adult population were being admitted in our hospital. ${ }^{12}$ Also, in present study males were more affected by adverse events (52\%) as compared to the female patients $(48 \%)$ these findings correlate well with other similar studies by Rajeshreddy et al, and Subbanna et al. ${ }^{22,23}$ However, some other studies have refuted sex differences among ADRs. ${ }^{6,24}$

Most common drug groups causing ADR were beta lactams $(22.66 \%)$ followed by NSAIDs $(18.66 \%)$, antiepileptic's (7.33\%) and quinolones (6.66\%). Among the organ systems affected cutaneous ADRs were most common (40.67\%) followed by generalized ADRs (37.34\%) and gastrointestinal ADRs (6.67\%). The findings from present study corroborate with other similar studies by Badyal et al, and Segal et al. ${ }^{25,26}$

Preventability assessment was carried out by Schumock and Thornton criteria and it was found that none of the ADRs were definitely preventable while majority of ADRs (86\%) were in the not preventable category and $14 \%$ of ADRs were in the probably preventable category. ${ }^{21}$

Severity assessment by Hartwig and Seigel scale revealed majority of ADR were of moderate severity $(76 \%)$ while $18 \%$ of ADRs were of mild severity only $6 \%$ of the reported ADRs were of severe category. ${ }^{20}$ Severe ADRs resulted in further increase in duration of hospitalization with only one death occurring. These results correlate well with other similar studies done by Vijaykumar et al, and Shareef et al. ${ }^{27,28}$

Rawlins and Thompson criteria were applied to classify the reported adverse events into type A and type B ADR and in present study results showed that majority of ADRs were type A (84\%) while only a few were type B ADRs (14\%) which correlated well with Rawlins classification. ${ }^{19}$

Causality assessment according to the WHO UMC causality assessment criteria17,18 revealed that none of the ADRs were in the definite/certain category as rechallenge with the suspected drug is not possible without the 
attendant risk to the life of patient, hence rechallenge is not done nowadays except under exceptional circumstances and that too with full precautions to resuscitate the patient if necessary, while probable/likely category $(57.34 \%)$ was the most common causality group followed by possible $(25.34 \%)$ group. These results corroborate well with other similar results published in literature by Sen et al. ${ }^{29}$

The present need of the hour is to ensure that regular sensitization of the healthcare personnel is done through conferences, seminars and CME and also by encouraging the healthcare professionals to report all the suspected ADRs in the hospital. Limitation of the present study was lack of adequate reporting by health care professionals which can be taken care of by following the above suggestions, also till now no technical associate has been provided by the PvPI to our AMC and that may be another reason for under reporting of adverse events from our AMC, inspite of these limitations all efforts are being put by the AMC personnel and concerned authorities at our AMC to ensure adequate reporting of adverse events from our Institute.

\section{CONCLUSION}

Present study revealed that age group of 21-40 years was most commonly involved $(46 \%)$ in adverse events and ADR were slightly more common in males (52\%) as compared to females. Also, majority of ADR were of moderate severity $(76 \%)$ and many were type A ADRs $(84 \%)$ and were of not preventable category $(86 \%)$. Cutaneous ADRs were most common type of ADRs (40.67\%) and antibiotics were most commonly implicated drug group causing ADRs (53.33\%).

In conclusion ADRs are an important cause of morbidity and mortality among patients taking medications for treatment of their diseases and they also contribute significantly to the economic burden on the society. Health care professionals have an important role to play in detecting and reporting of ADRS and their active contribution to pharmacovigilance is very much need of the hour without which the PvPI Programme cannot sustain and improve itself. The present study highlights the importance of reporting ADRs and aims to contribute to the improvement of pharmacovigilance activities at the regional level in Southern India under the PvPI from our Institute.

\section{ACKNOWLEDGEMENTS}

Authors would like to thank the Director/Dean and the Medical Superintendent of McGann teaching hospital for the support and encouragement during the period of study. Also, thanks to the HOD \& staff, Department of Pharmacology and Doctors, McGann teaching hospital for the support during the period of study.

Funding: No funding sources Conflict of interest: None declared
Ethical approval: The study was approved by the Institutional Ethics Committee

\section{REFERENCES}

1. Gupta SK. Textbook of pharmacovigilance. Institute of Clinical Research (India) 1st ed. New Delhi: Jaypee Publishers Pvt Ltd; 2011:13.

2. Pharmacovigilance: ensuring the safe use of medicines-WHO policy perspectives on medicines, No.009; Oct 2004. Available at: http://apps.who.int/medicinedocs/en/d/Js6164e/7.htm 1.

3. World Health Organization (WHO): safety of medicines- A guide to detecting and reporting adverse drug reactions-why health professionals need to take actions. Geneva. World Health Organization; 2002. Available at: http:// www.apps.who.int/medicinedocs (en/d/Jh2992e/6/html).

4. Glossary of pharmacovigilance terms. Available at: htps://www.who-umc.org/global-

pharmacovigilance/glossary.

5. Edwards IR, Aronson JK. Adverse drug reactions: definitions, diagnosis, and management. Lancet. 2000;356(9237):1255-9.

6. Jose J, Rao PGM. Pattern of adverse drug reactions notified by spontaneous reporting in an Indian tertiary care teaching hospital. Pharmacol Res. 2006;54(3):226-33.

7. Lazarou J, Pomeranz BH, Corey PN. Incidence of adverse drug reactions in hospitalized patients: A meta-analysis of prospective studies. JAMA 1998;279(15):1200-05.

8. Davies EC, Green CF, Taylor S, Williamson PR, Mottram DR, Pirmohammed M. Adverse drug reactions in hospital in-patients: a prospective analysis of 3695 patient episodes. PLoS One. 2009;4(2):e4439.

9. Rao PG, Archana B, Jose J. Implementation and results of an adverse drug reaction reporting programme at an Indian teaching hospital. Indian $\mathbf{J}$ Pharmacol. 2006;38(4):293.

10. Domecq C, Naranjo CA, Ruiz I, Busto U. Sex related variations in the frequency and characteristics of adverse drug reactions. Int $\mathrm{J}$ Clin Pharmacol Ther Toxicol. 1980;18(8):362-6.

11. Beard K. Adverse reactions as a cause of hospital admission in the aged. Drugs Aging. 1992;2(4):35667.

12. Martinez ML, Garcia LM, Palop V, Ferrer JM, Rubio E, Morales-Olivas FJ. A prospective study of adverse drug reactions in hospitalized children. $\mathrm{Br} \mathrm{J}$ Clin Pharmacol. 1999;47(6):681-88.

13. Simpson J M, Bateman D N, Rawlins M D. Using the adverse reactions register to study the effects of age and sex on adverse drug reactions. Stat Med. 1987;6(7):863-7.

14. Sumit Verma, Yogesh Gulati. Fundamentals of Pharmacovigilance. 1st ed. Hyderabad: Paras Medical Publishers; 2017:26. 
15. Pharmacovigilance Programme of India (PvPI). National Coordinating Centre (NCC) - Indian Pharmacopoeia Commission (IPC), Ghaziabad. Available at: http:// www.ipc.gov.in/PvPI/pv_home.html.

16. Pharmacovigilance Programme of India. CDSCO. Ministry of Health and Family Welfare, Govt of India; 2010. Available at: http:// www.cdsco.nic.in/pharmacovigilance.html.

17. The use of WHO-UMC system for standardized case causality assessment. Available at: http:// www.WHOUMC.org/media/2768/standardized case causality assessment.

18. Causality assessment algorithms and scales; 2005. Available at: http:// www. pharmacovigilance.co.in/causalityassessment.html.

19. Rawlins M D, Thompson J W. Mechanisms of adverse drug reactions. In Davies D M ed. Textbook of adverse drug reactions. Oxford. Oxford University Press; 1991: 18-45.

20. Hartwig SC, Seigel J, Schneider PJ. Preventability and severity assessment in reporting adverse drug reactions. Am J Hosp Pharm. 1992;49(9):2229-32.

21. Schumock GT, Thornton JP. Focusing on preventability of adverse drug reactions. Hosp Pharm. 1992;27:538.

22. Rajeshreddy SGSV, Patil LV. Causality assessment and the severity of the adverse drug reactions in a tertiary care hospital: a pharmacovigilance study. Int $\mathbf{J}$ Basic Clin Pharmacol. 2017;6:2800-3.

23. Subbanna P T, Chandy S J. Role of active surveillance in improving hospital adverse drug event monitoring. Indian J Pharmacol. 2006;38(5):363-4.
24. Rademaker M. Do women have more adverse drug reactions? Am J Clin Dermatol. 2001;2:349-51.

25. Badyal DK, Kanish B, Gulrez G. Causality assessment and pattern of adverse drug reactions in a tertiary care hospital. Int J Basic Clin Pharmacol. 2018;7:210-4.

26. Segal AR, Doherty KM, Leggott J, Zlotoff B. Cutaneous reactions of drugs in children. Pediatr. 2007;120(4):1082-96.

27. Vijaykumar TM, Dhanaraju MD. Description of adverse drug reactions in a multi-specialty teaching hospital. Int J Integr Med. 2013;1(26):1-6.

28. Shareef SM, Naidu CDM, Raikar SR, Rao YV, Devika U. Development, implementation and analysis of adverse drug reaction monitoring system in a rural tertiary care teaching hospital in Narketpally, Telangana. Int J Basic Clin Pharmacol. 2015;4(4):75760.

29. Sen M, Singh A, Misra M. Retrospective analysis of adverse drug reactions reported at ADR monitoring centre under PvPI in a tertiary care hospital. Int J Basic Clin Pharmacol. 2018;7:303-8.

Cite this article as: Sai NP. Analysis of adverse drug reactions in a tertiary care teaching hospital in Southern India. Int J Basic Clin Pharmacol 2019;8:934-9. 